\title{
Volatility Spillovers from the Chinese Stock Market to Economic Neighbours
}

\author{
David E. Allen ${ }^{\mathrm{a}, *}$, Ron Amram ${ }^{\mathrm{a},}$, and Michael McAleer ${ }^{\mathrm{b}}$ \\ ${ }^{a}$ School of Accounting, Finance and Economics, Edith Cowan University \\ ${ }^{b}$ Econometric Institute, Erasmus School of Economics, Erasmus University Rotterdam and Tinbergen Institute, \\ The Netherlands, Department of Quantitative Economics, Complutense University of Madrid, and Institute of \\ Economic Research, Kyoto University
}

\begin{abstract}
This paper examines whether there is evidence of spillovers of volatility from the Chinese stock market to its neighbours and trading partners, including Australia, Hong Kong, Singapore, Japan and USA. China's increasing integration into the global market may have important consequences for investors in related markets. In order to capture these potential effects, we explore these issues using an Autoregressive Moving Average (ARMA) return equation. A univariate GARCH model is then adopted to test for the persistence of volatility in stock market returns, as represented by stock market indices. Finally, univariate GARCH, multivariate VARMA-GARCH, and multivariate VARMA-AGARCH models are used to test for constant conditional correlations and volatility spillover effects across these markets. Each model is used to calculate the conditional volatility between both the Shenzhen and Shanghai Chinese markets and several other markets around the Pacific Basin Area, including Australia, Hong Kong, Japan, Taiwan and Singapore, during four distinct periods, beginning 27 August 1991 and ending 17 November 2010. The empirical results show some evidence of volatility spillovers across these markets in the pre-GFC periods, but there is little evidence of spillover effects from China to related markets during the GFC. This is presumably because the GFC was initially a US phenomenon, before spreading to developed markets around the globe, so that it was not a Chinese phenomenon.
\end{abstract}

Keywords: Volatility spillovers, VARMA-GARCH, VARMA-AGARCH, Chinese stock market.

\section{Introduction}

Over the past two decades, China has established itself as one of the world's leading economic powers. Its strong economic growth has seen it become one of the world's industrial superpowers. This growth has had a significant impact on other economies around the world through Chinese imports and exports. One economy that has been particularly affected by the strong Chinese growth is the Australian economy, as China relies heavily on Australia's rich mining and resources sector for its growing industries. The Chinese stock market has also grown significantly since its inception

${ }^{*}$ Corresponding author. Email d.allen@ecu.edu.au. Acknowledgements: For financial support, the first author acknowledges the Australian Research Council, and the third author is most grateful to the Australian Research Council, National Science Council, Taiwan, and the Japan Society for the Promotion of Science. 
in 1991 and has gone through many changes, both regulatory and operational. This paper examines whether there is evidence of spillovers of volatility from the Chinese stock market to its neighbours and trading partners, including Australia, Hong Kong, Singapore, Japan and USA. The paper will use the GARCH$(1,1)$, VARMA-GARCH and VARMA-AGARCH models to estimate volatility and determine evidence of volatility spillovers.

\section{Literature Review}

In 2003, approximately $1.1 \%$ of the world's $3.2 \%$ growth was attributed to China based on Purchasing Power Parity (PPP). China has been said to be the "manufacturing breadbasket of the world" Barth, (Koepp and Zhuo, [1, p. 2]). China has demonstrated strong growth, which is among the highest in the world, and has maintained it for over a decade. The Gross Domestic Product at the end of 2004 was more than 8 times its size in 1978, the year in which major economic reforms made a turning point in the previously-struggling economy. Such growth has led to China's GDP being the 6th largest in the world in 2004. Once the figures have been adjusted for PPP, China was the second largest in the world, after the USA (Barth, Koepp and Zhuo, [1]). It had also contributed to the fact that China's GDP has grown by at least 7\% per year since 1991 NBS, [6].

This economic reform was carried out by the then newly appointed leader, Deng Xiaoping, following the death of the Communist Party leader, Mao Zedong, in 1976, whose economic reform failures since 1949 (including collectivisation of farms and focus on heavy industry) had led to impoverishment and left China isolated from the global market (Breslin, [5]). Deng's 1978 economic reform has been described as "a watershed in Chinese economic policy" (Breslin, [1, p.1]. Barth, Koepp and Zhou [1, p1] state that 1978 was the year in which "China began taking its first tentative steps away from a centrally-planned communist economy towards a mixed socialist-market system", and as a result "has produced rapid growth in both GDP and exports, and has been supported by large flows of foreign private direct investment rather than external official assistance". In other words, China has opened itself to international trade more than ever before, and was richly rewarded for doing so.

In 2002, after several reforms, banks controlled approximately $80 \%$ of total financial assets. In addition, shares only accounted for about $15 \%$ of total financial assets (compared with $46 \%$ for USA), and approximately two-thirds of the shares listed on the Shenzhen and Shanghai stock exchanges, China's only two stock exchanges at the time, were government owned and non-tradable. Corporate bonds accounted for less than 1\% (Barth, Koepp and Zhou, [1. p. 4]). Such financial systems are often very sensitive to institutional failure and contagion, particularly as the 'big four', China's largest 4 banks, all state-owned, accounted for $59 \%$ of banking assets and about one-half of the total of national financial assets (Barth, Koepp and Zhou, 2004, [1, p. 7]), which would make funds difficult to obtain in the event of institutional failure.

To make matters worse, it is estimated that prior to the 1998 , more than $20 \%$ of total loans in the banking system were bad or non-performing (Chang, [7]). In addition, the lack of efficient capital markets implies that the allocation of capital to firms, and their investment decisions, is at the discretion of banks rather than markets. As a result, firms could obtain funds for sub-optimal investments, whereas in more efficient capital markets, the securities issued by those firms might suffer if their investments were sub-optimal, non-performing, or if a misuse of capital were to occur (See [1]).

Green [12] claims that, if China's economic growth is to be sustained in the long run, it must create effective financial institutions. There have been several reforms made by the Chinese govern- 
ment to try and develop a financial system that is better adjusted and secure. Green [12] identifies three distinct periods or phases of institutional change:

1. The first period is from the end of 1990 to the end of 1992 . In a move to try and create a more balanced financial system, the government opened two stock exchanges: Shanghai in late 1990, and Shenzhen in mid-1991. [1] states that this was one of the major reforms or innovations to the Chinese financial system in recent years. Nevertheless, although the exchanges were formed on "the status of a legal-person organization and not a government bureau" (Green, [12, p.9]), and were generally at the senior staff's discretion, the People's Bank Of China still maintained control of operational and policy issues. Green [12, p.9] claims this was simply a "proxy for control by municipal leaders", who were inexperienced at managing operations with such a capitalist nature and, due to the strong presence of communism in China, were fearful of its political and social implications. In 1992, Deng and the politburo had reassured the people of China that this was a necessary reform, which led to thousands of state-owned enterprises attempting to become shareholding companies. This, in turn, led to an escalation in prices and demand for IPO shares, with the number of listed companies more than tripling between 1992 and 1993 ( NBS, [12]). Unfortunately, officials had sold all IPO application forms on the black market. This led to the disturbances in Shenzhen known as ' 8.10 ' (short for 10th of August), which were considered to be some of the most serious social disturbances in China at the time. As a result, the issuing and listing of shares was suspended while the government tried to find a new way of regulating the stock market (Green, 2004, [12, pp. 10-11).

2. The second period Green [12] identifies is between the end of 1992 and 1996. Towards the end of 1992, the China Securities Regulatory Commission (CSRC) was established as the "capital market watchdog" (Yao, [29, p. 2]). As it was not established as a government body, it had not been included in the government budget and was not allowed to reprimand offenders and wrongdoers or publicise administrative regulation. This is confirmed by Yao [29, p.2], who states that "the stock market used to be highly speculative and government manipulated... government policy was the dominant factor (in the) China stock market and directly triggered a bull market". This resulted in the market becoming highly volatile (Green, [12]). Another important change during this period was the change in the foreign exchange rate system in China. The Chinese Yuan (RMB) was under the government's control, and was not fully convertible in the global market. When the government relaxed regulations and allowed the introduction of "Swap shops" (Breslin, 1998, [5, p.6]), an inconsistency was found between the official exchange rate of RMB5.76 per US dollar, and the swap shop rate which was closer to RMB9 per US dollar. A government initiative to align the two in 1994 resulted in the official exchange rate settling at RMB8.61 per US dollar, a depreciation of about $50 \%$. This depreciation of the RMB made Chinese exports more attractive and increased the flow of foreign funds into China (Breslin, [5]).

3. The third period identified by Green [12] stretches from mid-1996 to the present. [12] claims that:

"In 1997, radical institutional change occurred, resulting in the empowerment of the CSRC and its effective take-over of the exchanges. Given its new powers, the CSRC has been able to reduce market instability and orient development towards the central government leadership's priorities" (Green, [12, p.1]).

In 1996 and 1997, there have been a large number of new regulations put in place to reduce the volatility of the market and to reduce the incentives of government officials to manipulate it. $[12$, p.20] suggests these changes followed as the leaders of China have "become convinced of the deleterious effects of local regulation and ... the wider dangers to the stability of the financial 
system that came from the stock market actions of local leaders". In 1998, the CSRC has finally taken over "supervisory responsibility of securities market regulation from the PBOC" [1, p.17]. It also controlled all aspects of market development such as the introduction and research of new products and securities, the results of which are not all positive, as the exchanges "cannot innovate in a way that an exchange should ideally be allowed to... (They) have been operated more as divisions of the CSRC than as independent business" (Green, [12, p.24]).

One can claim that, despite the latter, the Chinese stock market operates more efficiently today than 10 years ago. Another important event was that China's 'big four' have also received over $\$ 33$ billion of capital from the government in order to help them eliminate non-performing loans and to minimise the impact of the Asian Financial Crisis [1, p.17].

China has become an important player in international markets, as demonstrated by Moon and $\mathrm{Yu}[26, \mathrm{p} .20]$, who state that:

"As the first and second largest economies in terms of purchasing power in the world, the US and China's integration and competition in global capital market will be important in global portfolio management, hedging and trading".

However, integration into the global market can involve spillover effects of returns and volatility across markets. This has been found to occur between China and several of its trading partners. Using a symmetric and asymmetric spillover GARCH approach, Moon and $\mathrm{Yu}[26]$ find evidence of volatility spillover effects between the USA and China, claiming that 'good news' from the USA will reduce the variance in China's stock returns. They also find evidence of symmetric volatility spillover effects from China to the USA, and through the USA into international markets.

Yi, Chen and Wong [30], who use a Fractionally Integrated Vector Error Correction Model with a multivariate GARCH model, and Johansson and Ljungwall [17], find evidence that the Chinese stock market has stronger ties with the neighboring Hong Kong market then it does with the USA, despite the size of the US economy, and that there are significant spillover effects for both returns and volatility among China, Hong Kong and Taiwan. This is supported by So and Tse [28], who assert that Asian markets are becoming increasingly integrated, and that there is evidence to suggest that their co-movements during periods of financial distress are becoming increasingly strong. Moon and $\mathrm{Yu}[26$, p.20] state that "China's stock market has more information influence on the international stock market transmission since December 2005 as its stock exchanges became more liquid, open and influential". This is also confirmed by Yilmaz [31], suggesting that China's stock market is one of significant importance within Asia and international markets.

The focus of our paper is on the impact of China's integration into the global market, and the extent to which it may involve spillover effects of returns and volatility across markets. This is of significance for several reasons:

1. It may affect the selection of shares for investors and fund managers who are interested in international equity, especially those interested in the Pacific-Basin area.

2. It may have an effect on portfolio optimization for investors and fund managers alike.

3. It may have implications for Australian markets. Australia's strong economic growth over the past decade (and of Western Australia, in particular), as well as its relative resilience during the recent GFC, has often been attributed to the corresponding growth in China. This is due to the fact that China has relied significantly on Australia's rich resource sector to fuel its industrial growth. Understanding the relationship of the volatilities of the two markets may have significant implications for Australian investors.

4. It may also have an effect on the pricing of financial assets. 


\section{Research Method}

\subsection{Data set and econometric models}

The data set includes daily data for each index from 27 August 1991, the earliest date where a complete market index for China became available, until 17 November 2010. The indexes are total market indexes, based on market capitalizations and are calculated by Datastream. Daily returns are calculated as follows:

$$
y_{i t}=\ln \left(p_{i t}\right)-\ln \left(p_{i t-1}\right)
$$

The data sets used are shown in Table 1.

\begin{tabular}{|c||c||c|}
\hline Country & Symbol & Abbreviation for \\
\hline \hline China & CHN & Chinese market \\
\hline \hline USA & US & American market \\
\hline \hline Australia & AUS & Australian market \\
\hline \hline Hong Kong & HK & Hong Kong market \\
\hline \hline Japan & JPN & Japanese market \\
\hline \hline Singapore & SNG & Singaporean market \\
\hline
\end{tabular}

Table 1: List of countries and indices

There are a variety of models used to test for the existence of time-varying volatility and for spillover effects in returns and volatility across markets. Manganelli and Engle [24] claim that the main difference between models is how they deal with the return distribution, and classify these models into three distinct groups:

- Parametric, such as RiskMetrics and GARCH;

- Nonparametric, such as Historical simulation and the Hybrid Model;

- Semiparametric, such as CAViaR, Extreme Value Theory, and Quasi-Maximum Likelihood GARCH.

In this paper, we adopt parametric techniques and use the $\operatorname{GARCH}(1,1)$, VARMA-GARCH and VARMA-AGARCH models for the empirical analysis.

\subsection{Univariate conditional volatility models}

Engle [8] developed the Autoregressive Conditional Heteroskedasticity (ARCH) model that incorporates all past error terms. It was generalised to GARCH by Bollerslev [3] to include lagged term conditional volatility. In other words, GARCH predicts that the best indicator of future variance is the weighted average of long-run variance, the predicted variance for the current period, and any new information in this period, as captured by the squared residuals (Engle, [9]).

The framework is developed as follows: consider a time series $y_{t}=E_{t-1}\left(y_{t}\right)+\varepsilon_{t}$, where $E_{t-1}\left(y_{t}\right)$ is the conditional expectation of $y_{t}$ at time $t-1$ and $\varepsilon_{t}$ is the error term. The GARCH model has the following specification: 


$$
\begin{gathered}
\varepsilon_{t}=\sqrt{h_{t} \eta_{t}}, \quad \eta_{t} \sim N(0,1) \\
h_{t}=\omega+\sum_{j=1}^{p} \alpha \varepsilon_{t-j}^{2}+\sum_{j=1}^{q} \beta_{j} h_{t-j}
\end{gathered}
$$

in which $\omega>0, \alpha_{j} \geq 0$ and $\beta_{j} \geq 0$, are sufficient conditions to ensure a positive conditional variance, $h_{t} \geq 0$. The ARCH effect is captured by the parameter $\alpha_{j}$, which represents the short run persistence of shocks to returns. $\beta_{j}$ captures the GARCH effect, and $\alpha_{j}+\beta_{j}$ measures the persistence of the impact of shocks to returns to long-run persistence. A GARCH $(1,1)$ process is weakly stationary if $\alpha_{j}+\beta_{j} \leq 1$.

Ling and McAleer [19] and Harris, Stoja and Tucker [15] claim that the GARCH model is "perhaps the most widely used approach to modeling the conditional covariance matrix of returns", and Engle [9] states it has been successful, even in its simplest form, in predicting conditional variance. The main advantage of this model is that it allows "a complete characterization of the distribution of returns and there may be spacefor improving their performance by avoiding the normality assumption" (Manganelli and Engle, [24] p.9). However, Engle [9] , Nelson [27] , Zhang and Li [32] and Harris, Stoja and Tucker [15] also outline some of the disadvantages of the GARCH model as follows:

- GARCH can be computationally burdensome and can involve simultaneous estimation of a large number of parameters.

- GARCH tends to underestimate risk (when applied to Value-at-Risk, VaR) as the normality assumption of the standardized residual does not always hold with the behaviour of financial returns.

- The specification of the conditional variance equation and the distribution used to construct the log-likelihood may be incorrect.

- GARCH rules out, by assumption, the negative leverage relationship between current returns and future volatilities, despite some empirical evidence to the contrary.

- GARCH assumes that the magnitude of excess returns determines future volatility, but not the sign (positive or negative returns), as it is a symmetric model. This is a significant problem as research by Nelson [27] and Glosten, Jagannathan and Runkle (GJR) [13] shows that asset returns and volatility do not react in the same way for negative information, or 'bad news', as they do for positive information, or 'good news', of equal magnitude.

In order to deal with these problems, a large number of variations on the basic GARCH model have been created, each one dealing with different issues. Bollerslev [4] developed a multivariate GARCH (MGARCH) model that asumes Constant Conditional Correlation (CCC). In other words, it assumes independence of asset returns' conditional variance. Multivariate GARCH (MGARCH) models have recently been used widely in risk management and sensitivity analysis.

Bauwens, Laurent and Rombouts [2] suggest that the most appropriate use of multivariate GARCH models is to model the volatility of one market with regard to the co-volatility of other markets. In other words, these models are used to see if the volatility of one market leads the volatility of other markets (the 'Spillover Effect'). They also assert that these models can be used 
to model the tangible effects of volatility, such as the impact of changes in volatility on exports and output growth rates. Bauwens, Laurent and Rombouts [2] suggest that these models are also efficient in determining whether volatility is transmitted between markets through the conditional variance (directly) or conditional covariances (indirectly), whether shocks to one market increase the volatility of another market, and the magnitude of that increase, and whether negative information has the same impact as positive information of equal magnitude.

Nelson [27] developed the Exponential GARCH (EGARCH) model. This model uses logarithms to ensure that the conditional variance is non-negative, and captures both the size and sign effects of shocks, capturing the effect of asymmetric returns on conditional volatility. This model was the first to capture the asymmetric impact of information. A second model, which is computationally less burdensome then Nelson's EGARCH, is the Glosten, Jagannathan and Runkle GJR model [13]. [13] found significant evidence of seasonal effects on the conditional variance in the NYSE ValueWeighted Index. Engle and Ng [10] claim that the GJR forecasts of volatility are more accurate than those of the EGARCH model.

The GJR model is specified as:

$$
h_{t}=\omega+\sum_{j=1}^{r}\left(\alpha_{j}+\gamma_{j} I\left(\varepsilon_{t-j}^{2}\right)\right) \varepsilon_{t-j}^{2}+\sum_{j=1}^{s} \beta_{j} h_{t-j}
$$

where

$$
I_{i t}=\left\{\begin{array}{ll}
0, & \varepsilon_{i t} \geq 0 \\
1, & \varepsilon_{i t}<0
\end{array}\right\}
$$

where $I_{i t}$ is an indicator function that distinguishes between positive and negative shocks of equal magnitude. In this model, when there is only one lag, that is, when $r=s=1$, the sufficient conditions to ensure that the conditional variance is positive $\left(h_{t}>0\right)$ are that $\omega>0, \alpha_{1} \geq$ $0, \alpha_{1}+\gamma_{1} \geq 0$,and $\beta_{1} \geq 0$; where $\alpha_{1}$ and $\left(\alpha_{1}+\gamma_{1}\right)$ measure the short run persistence of positive and negative shocks, respectively. These models can be estimated by maximum likelihood techniques when the errors follow a joint normal distribution. If this is not the case, quasi-maximum likelihood estimation (QMLE) can be used.

Necessary and sufficient conditions for the second order stationarity of the GARCH model

are $\sum_{i=1}^{r} \alpha_{i}+\sum_{i=1}^{s} \beta_{i}<1$, as demonstrated by Bollerslev (1986) [3]. The necessary and sufficient conditions for the GJR $(1,1)$ model were developed by Ling and McAleer [19], who showed that $E\left(\varepsilon_{t}^{2}\right)<\infty$ if $\alpha_{1}+\frac{\gamma_{1}}{2}+\beta_{1}<1$. Subsequently, McAleer et al. [22] demonstrated the log-moment condition for the GJR $(1,1)$ model, which is sufficient for consistency and asymptotic normality of the QMLE, namely $E\left(\log \left(\alpha_{1}+\gamma_{1} I\left(\eta_{t}\right) \eta_{t}^{2}+\beta_{1}\right)\right)<0$.

\subsection{Multivariate conditional volatility models}

We have considered univariate models of single assets in the previous section. However, in finance the behaviour of portfolios of assets is of primary interest. If we want to forecast the returns of portfolios of assets, we must consider the correlations and covariances between individual assets. A common approach adopted to the specification of multivariate conditional means and conditional variances of returns is as follows:

$$
y_{t}=E\left(y_{t} \mid F_{t-1}\right)+\varepsilon_{t}
$$




$$
\varepsilon_{t}=D_{t} \eta_{t}
$$

In (5) above, $y_{t}=\left(y_{1 t}, \ldots ., y_{m t}\right)^{\prime}, \quad \eta_{t}=\left(\eta_{i t}, \ldots \ldots, \eta_{m t}\right)^{\prime}$, a sequence of (i.i.d) random vectors, $F_{t}$ is a vector of past information available at time $t, D_{t}=\operatorname{diag}\left(h_{1}^{1 / 2}, \ldots \ldots ., h_{m}^{1 / 2}\right), m$ is the number of returns, and $t=1, \ldots, n$. (For a full exposition, see Li, Ling and McAleer [19], McAleer [20] and Bauwens et al [2]. The Bollerslev [4] constant conditional correlation (CCC) model assumes that the conditional variance of each return, $h_{i t}, i=1, \ldots, m$, follows a univariate GARCH process:

$$
h_{i t}=\omega+\sum_{j=1}^{r} \alpha_{i j} \varepsilon_{i, t-j}^{2}+\sum_{j=1}^{s} \beta_{i j} h_{i . t-j}
$$

In (6) above, $\alpha_{i j}$ represents the ARCH effect, or the short run persistence of shocks to return $i$, and $\beta_{i j}$ captures the GARCH effect; the impact of shocks to return $i$ on long run persistence, given by:

$$
\sum_{j=1}^{r} \alpha_{i j}+\sum_{j=1}^{s} \beta_{i j}
$$

It follows that the conditional correlation matrix of CCC is $\Gamma=E\left(\eta_{t} \eta_{t}^{\prime} \mid F_{t-1}\right)=E\left(\eta_{t} \eta_{t}^{\prime}\right)$, where $\Gamma=\left\{\rho_{i t}\right\}$ for $i, j=1, \ldots, m$. From (5), $\varepsilon_{t} \epsilon_{t}^{\prime}=D_{t} \eta_{t} \eta_{t}^{\prime} D_{t}, \quad D_{t}=\left(\operatorname{diag} Q_{t}\right)^{1 / 2}$, and $E\left(\varepsilon_{t} \varepsilon_{t}^{\prime} \mid F_{t-1}\right)=$ $Q_{t}=D_{t} \Gamma D_{t}$, where $Q_{t}$ is the conditional covariance matrix, $\Gamma=D_{t}^{-1} Q_{t} D_{t}^{-1}$ is the conditional correlation matrix and the individual conditional correlation coefficients are calculated from the standardised residuals in equations (5) and (6). This means that there is no multivariate estimation required in CCC, which involves $m$ univariate GARCH models, except in the case of the calculation of conditional correlations.

One limitation of this approach is that it presumes that the conditional variances are independent across returns, and there is no inclusion of asymmetric behaviour. Ling and McAleer [19] suggest a vector autoregressive moving average (VARMA) specification of the conditional mean in (5):

$$
\Phi(L)\left(Y_{t}-\mu\right)=\Psi(L) \varepsilon_{t}
$$

and specify the conditional variance as follows:

$$
H_{t}=W+\sum_{i=1}^{r} A_{i} \vec{\varepsilon}_{t-i}+\sum_{i=1}^{s} B_{j} H_{t-j}
$$

where $H_{t}=\left(h_{1 t}, \ldots \ldots, h_{m t}\right)^{\prime}, \vec{\varepsilon}_{t}=\left(\varepsilon_{1 t}^{2}, \ldots \ldots ., \varepsilon_{m t}^{2}\right)^{\prime}$, and $W, A_{i}$ for $i=1, \ldots ., r$, and $B_{j}$ for $j=$ $1, \ldots, s$ are $m \times m$ matrices. The VARMA-GARCH model assumes that shocks, whether positive or negative, have identical impacts on the conditional variance. To address this issue, McAleer, Hoti and Chan [25] suggested a VARMA-AGARCH specification for the conditional variance:

$$
H_{t}=W+\sum_{i=1}^{r} A_{i} \vec{\varepsilon}_{t-1}+\sum_{i=1}^{r} C_{i} I_{t-i} \vec{\varepsilon}_{t-i}+\sum_{i=1}^{s} B_{i} H_{t-j}
$$

where $C_{i}$ are $m \times m$ matrices for $i=1, \ldots, r$, and $I_{t}=\operatorname{diag}\left(I_{1 t}, \ldots, I_{m t}\right)$, where 


$$
I_{i t}=\left\{\begin{array}{ll}
0, & \varepsilon_{i t}>0 \\
1, & \varepsilon_{i t} \leq 0
\end{array}\right\}
$$

VARMA-AGARCH reduces to VARMA-GARCH when $C_{i}=0$ for all $i$. If $C_{i}=0$ and $A_{i}$ and $B_{j}$ are diagonal matrices for all $i$ and $j$, then VARMA-GARCH reduces to the CCC model. The parameters of the model can be estimated using maximum-likelihood estimation if a joint normal density function applies, and when $\eta_{t}$ does not follow a joint multivariate distribution, quasi-maximumlikelihood estimation (QMLE) can be applied.

\subsection{Model specifications}

Our goal in this paper is to model spillover effects. We begin with simple univariate models before advancing to more complex multivariate ones. In the context of measuring asymmetric shocks and spillover effects, the following models have been proposed:

1. The GARCH model is estimated with an auxiliary term added to capture spillover effects:

$$
h_{A U S, t}=\omega+\alpha \epsilon_{A U S, t-1}^{2}+\beta_{1} h_{A U S . t-1}+\beta_{2} \epsilon_{C H N, t-1}^{2}
$$

The null hypothesis is that there is no conditional volatility or a spillover effect. The alpha and first beta test for GARCH effects in Australia. The second beta is an additional term used to capture the effect of the lagged squared residuals of a GARCH $(1,1)$ on a Chinese index, and added to the Australian market equation to test for spillover effects, as suggested by Hamao, Masulis and $\mathrm{Ng}$ [14]. If the coefficients are statistically significant then there is a spillover effect of volatility from China to Australia.

2. The multivariate VARMA GARCH model of Ling and McAleer [19] will also be used to model the conditional correlation of volatility between the aforementioned markets. The VARMA-GARCH model can be written as follows:

$$
h_{A U S, t}=\omega+\alpha_{1} \varepsilon_{A U S, t-1}^{2}+\beta_{1} h_{A U S, t-1}+\alpha_{2} \varepsilon_{C H N, t-1}^{2}+\beta_{2} h_{C H N, t-1}+\eta_{t}
$$

The alpha 2 and beta 2 measure the market's volatility relation to the lagged squared innovation and lagged forecast volatility of the Chinese market. The null hypothesis is that these coefficients are equal to zero, and there is no spillover of volatility from China to the other markets.

3. The multivariate VARMA-AGARCH model will be used to model the conditional correlation of volatility between these markets. The equation for the VARMA-AGARCH is expressed as:

$$
h_{A u s, t}=\alpha_{1 A} \varepsilon_{A u s, t-1}^{2}+\alpha_{1 B}\left(\varepsilon_{A u s, t-1}^{2} \times\left(\varepsilon_{A u s, t-1}^{2}<0\right)\right)+\beta_{1} h_{A u s, t-1}+\alpha_{2} \varepsilon_{C H N, t-1}^{2}+\beta_{2} h_{C H N, t-1}
$$

The alpha 1A and alpha 1B represent the relationship between a market's volatility and its own lagged positive and negative returns, respectively. The beta 1 measures the GARCH effect, while alpha 2 and beta 2 measure the spillovers of volatility from the Chinese market. The null hypothesis is that there is no asymmetric relationship between returns and also no spillovers.

The results from the empirical application of these three models are presented in the next section. 


\section{Empirical results}

The characteristics of the basic index series used in our data set presented in Table 2 suggest the existence of non-normality and fat tails. The Jarque-Bera Lagrange Multiplier test rejects the null hypothesis that the data are normally distributed: the p-values for all indexes above are zero. This is also evident from the skewness and excess kurtosis of the data. In order to estimate the parameters in the GARCH models, the Quasi-Maximum Likelihood Estimator (QMLE) will be used.

\begin{tabular}{|c|c|c|c|c|c|c|}
\hline & CHN & US & AUS & HK & JPN & SNG \\
\hline \hline Mean & 0.000610 & 0.000247 & 0.000291 & 0.000347 & -0.000001 & 0.000241 \\
\hline Median & 0.0000 & 0.000325 & 0.000413 & 0.000126 & -0.000007 & 0.000456 \\
\hline Maximum & 0.29827 & 0.10902 & 0.083785 & 0.15561 & 0.11533 & 0.10618 \\
\hline Minimum & -0.39525 & -0.094087 & -0.15977 & -0.13579 & -0.08762 & -0.095464 \\
\hline Skewness & 0.2388 & -0.23809 & -0.86304 & -0.06655 & 0.093215 & -0.091478 \\
\hline Excess Kurtosis & 29.780 & 9.1927 & 11.481 & 8.3948 & 3.8234 & 6.6823 \\
\hline Standard Deviation & 0.024645 & 0.011633 & 0.13834 & 0.016021 & 0.014234 & 0.012877 \\
\hline Coefficient of Variation & 40.392 & 47.027 & 47.566 & 46.126 & 1134.7 & 53.475 \\
\hline Jarque-Bera & 185442 & 17712.7 & 28175.3 & 14735.4 & 3063.18 & 9341.36 \\
\hline Probability & 0.000000 & 0.000000 & 0.000000 & 0.000000 & 0.000000 & 0.000000 \\
\hline
\end{tabular}

Table 2: Descriptive statistics

Before we conduct the GARCH tests we test for the existence of ARCH effects in the data sets. The results are shown below in Table 3 and display clear evidence of significant ARCH effects in all of the index series.

\begin{tabular}{|c|c|c|c|}
\hline Market & Test Statistic (LM) & $\mathrm{p}$ value & ARCH effect \\
\hline \hline CHN & 57.3636 & 0.000000 & Yes \\
\hline US & 218.126 & 0.000000 & Yes \\
\hline AUS & 259.533 & 0.000000 & Yes \\
\hline JPN & 61.194 & 0.000000 & Yes \\
\hline HK & 557.51 & 0.000000 & Yes \\
\hline SNG & 322.413 & 0.000000 & Yes \\
\hline
\end{tabular}

Table 3: Test results for ARCH effects

The results in Table 3 mean we can proceed with confidence to the GARCH analysis; which is broken down into several parts. First, a GARCH $(1,1)$ model is used to model conditional volatility and spillovers between the Chinese indexes and each of the other indexes during the four periods; 1990-1992, 1993-1996, 1997-2006, and 2007-2010. The process is repeated using the VARMAGARCH model and the VARMA-AGARCH model. Finally, the results of all three models are compared and contrasted. The results for all models use the Bollerslev-Wooldridge robust standard errors and covariances. 


\subsection{GARCH Models}

\begin{tabular}{|c|c|c|c|c|c|}
\hline & $\varpi$ (Constant) & $\alpha$ (alpha) & $\beta_{1}$ (Beta 1) & $\beta_{2}$ (Beta 2) & R- Squared \\
\hline \hline AUS & -0.000001 & 0.01101 & 1.015456 & 0.000543 & 0.015238 \\
\hline Z Score & -3.239940 & -4.087043 & 1003.982 & 1003.982 & \\
\hline P Value & 0.0012 & 0.0000 & 0.0000 & 0.0112 & \\
\hline HK & 0.000059 & 0.128870 & 0.181885 & 0.001097 & 0.000140 \\
\hline Z Score & 1.264000 & 1.043617 & 0.331561 & 0.366748 & \\
\hline P Value & 0.2062 & 0.2967 & 0.7402 & 0.7138 & \\
\hline JPN & 0.000128 & 0.094299 & 0.505810 & 0.004447 & 0.008064 \\
\hline Z Score & 1.220735 & 0.825650 & 1.282294 & -1.977698 & \\
\hline P Value & 0.2222 & 0.4090 & 0.1997 & 0.0480 & \\
\hline SNG & -0.000001 & -0.019306 & 1.020379 & 0.000374 & 0.015446 \\
\hline Z Score & -1.249494 & -122.7853 & 96.13132 & 350.3174 & \\
\hline P Value & 0.2115 & 0.0000 & 0.0000 & 0.0000 & \\
\hline US & 0.000012 & 0.014161 & 0.689467 & 0.001432 & 0.002512 \\
\hline Z Score & 0.974775 & 0.345332 & 2.319987 & 0.932055 & \\
\hline P Value & 0.3297 & 0.7298 & 0.0203 & 0.3513 & \\
\hline
\end{tabular}

Table 4: GARCH period $1(\mathbf{2 7} / \mathbf{0 8} / \mathbf{1 9 9 1 - 3 0 / 0 6 / 1 9 9 2 )}$

If we consider Australia first, we can see in Table 4 above that the constant and $\alpha$ and $\beta_{1}$ are all statistically significant at the $99 \%$ confidence level. The $\beta_{2}$ coefficient is significant at the $95 \%$ confidence level. The significance of the coefficients suggests that there is evidence of conditional volatility. The AUS index demonstrates evidence of a significant relationship between current volatility and lagged volatility and lagged residuals. It also demonstrates some evidence of volatility spillovers, as $\beta_{2}$ is statistically significant; a movement of $1 \%$ in volatility in CHN will cause AUS to move in the same direction by $0.000543 \%$ the following day. Although the spillover appears to be significant, its magnitude is extremely small. The predictive power of the equation or $\mathrm{R}$-squared is 0.015238 , which means the GARCH equation explains only about $1.5 \%$ of variations in the AUS volatility. The case of Hong Kong is different and none of the coefficients is statistically significant. This suggests no evidence of GARCH effects in the HK index and hence no spill-over effects.

The results for Japan are similar with none of the GARCH terms related to the Japanese index appearing to be significant. However, there is a significant $\beta_{2}$ coefficient, indicating some spillover effects from China. The equation for Singapore shows very significant GARCH effects and spillover effects from China. In the case of the USA, there is no evidence of spillover affects from China during this period. 


\begin{tabular}{|c|c|c|c|c|c|}
\hline & $\omega$ (Constant) & $\alpha$ (alpha) & $\beta_{1}$ (Beta 1) & $\beta_{2}$ (Beta 2) & R- Squared \\
\hline \hline AUS & 0.000002 & 0.033204 & 0.946869 & -0.000192 & 0.000361 \\
\hline Z Score & 2.955449 & 4.192184 & 78.47081 & -1.501074 & \\
\hline P Value & 0.0031 & 0.0000 & 0.0000 & 0.1333 & \\
\hline HK & 0.000003 & 0.078727 & 0.902878 & 0.000756 & 0.001178 \\
\hline Z Score & 3.739330 & 7.218294 & 75.31629 & 1.810342 & \\
\hline P Value & 0.0002 & 0.0000 & 0.0000 & 0.0702 & \\
\hline JPN & 0.000005 & 0.111364 & 0.857851 & -0.000403 & 0.006312 \\
\hline Z Score & 4.971117 & 7.629340 & 45.47051 & -2.738863 & \\
\hline P Value & 0.0000 & 0.0000 & 0.0000 & 0.0062 & \\
\hline SNG & 0.000018 & 0.206473 & 0.566906 & -0.000175 & 0.000251 \\
\hline Z Score & 5.266054 & 6.297598 & 8.982410 & -0.884600 & \\
\hline P Value & 0.0000 & 0.0000 & 0.0000 & 0.3764 & \\
\hline US & 0.000001 & 0.041874 & 0.919056 & 0.000003 & 0.008742 \\
\hline Z Score & 2.905635 & 4.226445 & 47.17074 & 0.628755 & \\
\hline P Value & 0.0037 & 0.0000 & 0.0000 & 0.5295 & \\
\hline
\end{tabular}

Table 5: GARCH period $2(\mathbf{1} / \mathbf{0 7} / \mathbf{1 9 9 2 - 3 1 / 1 2 / 1 9 9 6 )}$

Table 5 shows the GARCH model results for period 2 running from 1/7/1992 until 31/12/1996. The Australian GARCH model performs strongly in this period with all terms highly significant, but there is no evidence of any spillover from China. The model for Hong Kong is similarly significant, but here there is only evidence of spillover from China at a $10 \%$ level. The Japanese market has a strongly signifcant GARCH model, with very significant evidence of spillover effects from the Chinese market. All the terms in the GARCH model for the Singapore market in this period are significant, but there is no sign of any spillover effects from China. Finally, the US market is similar to the Singapore market; all its own terms in the mode are significant, but there is no influence from the Chinese market. 


\begin{tabular}{|c|c|c|c|c|c|}
\hline & $\omega$ (Constant) & $\alpha$ (alpha) & $\beta_{1}$ (Beta 1) & $\beta_{2}$ (Beta 2) & R- Squared \\
\hline \hline AUS & 0.000009 & 0.158612 & 0.821802 & 0.003470 & -0.003185 \\
\hline Z Score & 2.501231 & 6.219051 & 31.93894 & 0.912815 & \\
\hline P Value & 0.0124 & 0.0000 & 0.0000 & 0.3613 & \\
\hline HK & 0.000002 & 0.103348 & 0.887053 & 0.002888 & -0.004849 \\
\hline Z Score & 1.630384 & 6.453084 & 54.11003 & 1.016264 & \\
\hline P Value & 0.1030 & 0.0000 & 0.0000 & 0.3095 & \\
\hline JPN & 0.000004 & 0.098620 & 0.880742 & 0.000729 & 0.033774 \\
\hline Z Score & 2.388761 & 6.498459 & 51.28362 & & \\
\hline P Value & 0.0169 & 0.0000 & 0.0000 & 0.7778 & \\
\hline SNG & 0.000001 & 0.110133 & 0.881701 & 0.002203 & 0.002826 \\
\hline Z Score & 1.629113 & 6.688460 & 53.42511 & 1.078050 & \\
\hline P Value & 0.1033 & 0.0000 & 0.0000 & 0.2810 & \\
\hline US & 0.000002 & 0.082463 & 0.903541 & 0.001535 & 0.015010 \\
\hline Z Score & 3.026172 & 6.361093 & 65.06231 & 0.869435 & \\
\hline P Value & 0.0025 & 0.0000 & 0.0000 & 0.3846 & \\
\hline
\end{tabular}

Table 6: GARCH period 3 (1/01/1997-29/12/2006)

In period 3 which spans 1/1/1997 until 29/12/2006, the results are virtually identical to those in the previous period for the vanilla GARCH model. The GARCH models for the individual domestic markets are all highly significant but no terms to capture spillover effects from the Chinese market are significant

\begin{tabular}{|c|c|c|c|c|c|}
\hline & $\omega$ (Constant) & $\alpha$ (alpha) & $\beta_{1}$ (Beta 1) & $\beta_{2}$ (Beta 2) & R- Squared \\
\hline \hline AUS & 0.000009 & 0.158612 & 0.821802 & 0.003470 & -0.003185 \\
\hline Z Score & 2.501231 & 6.219051 & 31.93894 & 0.912815 & \\
\hline P Value & 0.0124 & 0.0000 & 0.0000 & 0.3613 & \\
\hline HK & 0.000002 & 0.103348 & 0.887053 & 0.002888 & -0.004849 \\
\hline Z Score & 1.630384 & 6.453084 & 54.11003 & 1.016264 & \\
\hline P Value & 0.1030 & 0.0000 & 0.0000 & 0.3095 & \\
\hline JPN & 0.000004 & 0.09862 & 0.880742 & 0.000729 & 0.033774 \\
\hline Z Score & 2.388761 & 6.498459 & 51.28362 & 0.282184 & \\
\hline P Value & 0.0169 & 0.0000 & 0.0000 & 0.7778 & \\
\hline SNG & 0.000001 & 0.110133 & 0.881701 & 0.002203 & 0.002826 \\
\hline Z Score & 1.629113 & 6.688460 & 53.42511 & 1.078050 & \\
\hline P Value & 0.1033 & 0.0000 & 0.0000 & 0.2810 & \\
\hline US & 0.000002 & 0.082463 & 0.903541 & 0.001535 & 0.015010 \\
\hline Z Score & 3.026172 & 6.361093 & 65.06231 & 0.869435 & \\
\hline P Value & 0.0025 & 0.0000 & 0.0000 & 0.3846 & \\
\hline
\end{tabular}

Table 7: GARCH period 4 (1/01/2007-17/11/20010)

Table 8 presents the results for period 4, which includes the GFC. Once again, all the individual domestic market GARCH model terms are highly significant, with the exceptions of the intercept 
terms in the cases of Hong Kong and Singapore. However, there is no evidence of any spillover effects from China.

\begin{tabular}{|c|c|c|c|c|c|}
\hline & $\omega$ (constant) & $\alpha_{i, t-1}$ (alpha 1) & $\beta_{i, t-1}$ (beta 1) & $\alpha_{C H N, t-1}$ (alpha 2) & $\beta_{C H N, t-1}$ \\
\hline \hline AUS & -0.000002 & 0.006957 & 0.998936 & 0.000692 & -0.000167 \\
\hline Z-score & -3.361702 & 0.304262 & 35.65696 & 0.778542 & 0.160367 \\
\hline P-value & 0.0008 & 0.7609 & 0.0000 & 0.4362 & 0.8726 \\
\hline HK & 0.000032 & 0.177097 & 0.495413 & -0.000413 & -0.001964 \\
\hline Z-score & 481.4134 & 2.33686 & 6.739542 & -0.365513 & -2.94666 \\
\hline P-value & 0.0000 & 0.0194 & 0.0000 & 0.7147 & 0.0032 \\
\hline SNG & 0.000008 & 0.035644 & 0.813999 & 0.000389 & -0.000178 \\
\hline Z-score & 0.458199 & 0.729455 & 2.288823 & 0.365212 & -0.100398 \\
\hline P-value & 0.6468 & 0.4657 & 0.0221 & 0.7150 & 0.9200 \\
\hline JPN & 0.000085 & 0.181919 & 0.381895 & -0.001553 & -0.002582 \\
\hline Z-score & 613.9881 & 1.629019 & 3.100160 & -1.726065 & -2.578897 \\
\hline P-value & 0.0000 & 0.1033 & 0.0019 & 0.0843 & 0.0099 \\
\hline US & 0.000031 & 0.004678 & 0.160328 & 0.000286 & 0.004257 \\
\hline Z-score & 0.807692 & 0.118240 & 0.160674 & 0.147930 & 0.499976 \\
\hline P-value & 0.4193 & 0.9059 & 0.8723 & 0.8824 & 0.6171 \\
\hline
\end{tabular}

Table 8: VARMA-GARCH with each market period 1 (27/08/1991)-(30/6/1992)

Table 8 presents the results for the VARMA-GARCH model for period 1 spanning 27/8/991 until 30/6/1992. This more sophisticated model captures the effects of both shocks to volatility in the Chinese market with $\alpha_{2}$ and the impact of predicted volatility in the Chinese market in the form of $\beta_{2}$. The results for this model are much more variable than in the original vanilla GARCH model. In the cases of the Singapore and US markets the intercepts are not significant. The estimate of $\alpha_{1}$ is only significant in the Hong Kong market. The $\beta_{1}$ values are significant in all markets except the USA. Shocks to the Chinese market, as captured by the $\alpha_{2}$ term, are not significant in any market save the Japanese one, and here the coefficient is only significant at $10 \%$. However, the forecasts of volatility in the Chinese market are significant at $1 \%$ in the cases of Hong Kong and Japan. 


\begin{tabular}{|c|c|c|c|c|c|}
\hline & $\omega$ (constant) & $\alpha_{i, t-1}$ (alpha 1) & $\beta_{i, t-1}$ (beta 1) & $\alpha_{C H N, t-1}$ (alpha 2) & $\beta_{C H N, t-1}$ \\
\hline \hline AUS & -0.0000001 & 0.003333 & 1.000362 & -0.000377 & 0.000196 \\
\hline Z-score & -0.772955 & 1.661506 & 325.1779 & -2.197541 & 0.957510 \\
\hline P-value & 0.4395 & 0.0966 & 0.0000 & 0.0280 & 0.3383 \\
\hline HK & 0.000004 & 0.067778 & 0.915817 & 0.001985 & -0.002125 \\
\hline Z-score & 1.786717 & 3.545568 & 41.89449 & 1.323161 & -0.945070 \\
\hline P-value & 0.0740 & 0.0004 & 0.0000 & 0.1858 & 0.3446 \\
\hline SNG & 0.000002 & 0.228749 & 0.495795 & -0.000248 & 0.000188 \\
\hline Z-score & 3.495807 & 4.462806 & 5.176507 & -2.145951 & 0.147572 \\
\hline P-value & 0.0005 & 0.0000 & 0.0000 & 0.0319 & 0.8827 \\
\hline JPN & 0.000003 & 0.096651 & 0.880038 & -0.000710 & 0.001111 \\
\hline Z-score & 9.347676 & 3.799058 & 45.68001 & -2.282139 & 1.936312 \\
\hline P-value & 0.0000 & 0.0001 & 0.0000 & 0.0225 & 0.0528 \\
\hline US & 0.000001 & 0.041413 & 0.921843 & -0.000062 & 0.000220 \\
\hline Z-score & 1.330267 & 2.518724 & 26.64947 & -0.851849 & 1.076851 \\
\hline P-value & 0.1834 & 0.0118 & 0.0000 & 0.3943 & 0.2815 \\
\hline
\end{tabular}

Table 9: VARMA-GARCH period $2(01 / 07 / 1992-31 / 12 / 1996)$

Table 9 reports the VARMA-GARCH results for period 2, and again the model displays mixed results. In two cases, Australia and the USA, the intercept terms are not significant. Past domestic shocks to volatility and forecasts of domestic volatility are significant in all markets. In three cases, Australia, Singapore and Japan, shocks to Chinese volatility have an impact in these domestic markets, while forecasts of volatility in China only appear to have a significant impact on the Japanese market.

\begin{tabular}{|c|c|c|c|c|c|}
\hline & $\omega$ (constant) & $\alpha_{i, t-1}$ (alpha 1) & $\beta_{i, t-1}$ (beta 1) & $\alpha_{C H N, t-1}$ (alpha 2) & $\beta_{C H N, t-1}$ \\
\hline \hline AUS & 0.000005 & 0.068058 & 0.891331 & 0.001820 & -0.005219 \\
\hline Z-score & 3.084611 & 3.476846 & 33.75763 & 0.640196 & -1.166832 \\
\hline P-value & 0.0020 & 0.0005 & 0.0000 & 0.5220 & 0.2433 \\
\hline HK & 0.0000009 & 0.068488 & 0.928221 & 0.003636 & -0.002161 \\
\hline Z-score & 0.962677 & 5.967149 & 97.88430 & 0.777195 & -0.258274 \\
\hline P-value & 0.3357 & 0.0000 & 0.0000 & 0.4370 & 0.7962 \\
\hline SNG & 0.000002 & 0.102826 & 0.891599 & 0.001668 & -0.000765 \\
\hline Z-score & 1.426325 & 6.751911 & 60.84168 & 0.297895 & -0.086207 \\
\hline P-value & 0.1538 & 0.0000 & 0.0000 & 0.7658 & 0.9313 \\
\hline JPN & 0.000008 & 0.080751 & 0.889785 & 0.007837 & -0.016061 \\
\hline Z-score & 3.348767 & 5.333640 & 45.45763 & 1.210317 & -1.539864 \\
\hline P-value & 0.0008 & 0.0000 & 0.0000 & 0.2262 & 0.1236 \\
\hline US & -0.0000002 & 0.066360 & 0.928184 & -0.002345 & 0.007318 \\
\hline Z-score & -0.421861 & 5.584735 & 81.84191 & -0.914778 & 1.561114 \\
\hline P-value & 0.6731 & 0.0000 & 0.0000 & 0.3603 & 0.1185 \\
\hline
\end{tabular}

Table 10: VARMA-GARCH period 3 (01.01/1997-29/12/2006) 
Table 10 displays the results for period 3 for the VARMA-GARCH model, and once again the results are mixed. The intercept terms are only significant in the cases of the Australian and Japanese markets. All the domestic market coefficients for past shocks to volatility and past forecasts of volatility are highly significant. Spillover effects are not present in the form of any significance being attached to past shocks to volatility in the Chinese market and predicted volatility in the Chinese market also has no impact.

Table 11 displays the results for period 4, which spans 1/1/2007 to $17 / 11 / 2010$ and includes the GFC. The results here are disappointing. The domestic market based GARCH models work well with all terms highly significant, with the exceptions of the intercept terms for Hong Kong, Singapore, Japan and the USA. None of the terms representing the impact of shocks or past forecasts of volatility in the Chinese market are significant at all. Thus, there is no evidence of any volatility spillovers at all in the period of the GFC when this VARMA-GARCH model is used.

\begin{tabular}{|c|c|c|c|c|c|}
\hline & $\omega$ (constant) & $\alpha_{i, t-1}$ (alpha 1) & $\beta_{i, t-1}$ (beta 1) & $\alpha_{C H N, t-1}$ (alpha 2) & $\beta_{C H N, t-1}$ \\
\hline \hline AUS & 0.000011 & 0.172235 & 0.805199 & 0.003191 & 0.001757 \\
\hline Z-score & 1.837049 & 5.192712 & 22.460000 & 0.200638 & 0.081728 \\
\hline P-value & 0.0662 & 0.0000 & 0.0000 & 0.8410 & 0.9349 \\
\hline HK & 0.000002 & 0.105062 & 0.883307 & -0.000816 & 0.006845 \\
\hline Z-score & 0.766595 & 4.362499 & 37.39593 & -0.123543 & 0.581266 \\
\hline P-value & 0.4433 & 0.0000 & 0.0000 & 0.9017 & 0.5611 \\
\hline SNG & 0.000001 & 0.11514 & 0.874042 & -0.000370 & 0.005299 \\
\hline Z-score & 0.670156 & 4.559480 & 36.90053 & -0.068106 & 0.687857 \\
\hline P-value & 0.5028 & 0.0000 & 0.0000 & 0.9467 & 0.4915 \\
\hline JPN & 0.000004 & 0.106728 & 0.867952 & -0.001487 & 0.005228 \\
\hline Z-score & 1.393998 & 3.821262 & 27.59132 & -0.304728 & 0.656833 \\
\hline P-value & 0.1633 & 0.0000 & 0.0000 & 0.7606 & 0.5113 \\
\hline US & 0.000001 & 0.095252 & 0.888238 & -0.000184 & 0.005836 \\
\hline Z-score & 0.658203 & 4.480209 & 39.74335 & -0.034869 & 0.57721 \\
\hline P-value & 0.5104 & 0.0000 & 0.0000 & 0.9722 & 0.5638 \\
\hline
\end{tabular}

Table 11: VARMA-GARCH period $4(\mathbf{0 1 . 0 1 / 2 0 0 7 - 1 7 / 1 1 / 2 0 1 0 )}$

Table 12 presents the results of the VARMA-AGARCH model for period 1 from 27/8/1991 until $30 / 6 / 1992$. This is the most sophisticated model applied because it incorporates leverage effects, permitting different responses to past positive and negative shocks to volatility in the local market. For Australia, the results are mixed. The intercept and coefficient $\alpha_{1 A}$, which captures the impact of past positive shocks, are insignificant. The $\alpha_{1 B}$ coefficient which captures the influence of past negative shocks to the Australian market, is very significant, as are the influence of past forecasts of volatility in the Australia market, and past shocks to volatility in the Chinese market, as captured by the coefficient $\alpha_{2}$, which is significant at $10 \%$. The result for Hong Kong in this first period is weak, with the intercept coefficient, past forecasts of volatility in the Hong Kong market significant and past forecasts of volatility in the Chinese market marginally significant at $10 \%$. The result for Singapore has a significant intercept, a significant coefficient for past positive shocks, a significant coefficient on past forecasts of volatility in the Singapore market, and a significant coefficient on previous shocks in the Chinese market. The results for the Japanese market in this period are similar, with a significant intercept, a significant coefficient on past forecasts of volatility, though 
not on past domestic Japanese shocks, but a very significant coefficient on past forecasts of volatility in China, and a significant coefficient, at the $10 \%$ level, on previous shocks to volatility in China. The results for the US market are strange, with none of the coefficients appearing to be significant.

\begin{tabular}{|c||c||c||c||c||c||c|}
\hline & $\omega$ (constant) & $\alpha_{i 1, t-1}($ alpha 1A) & $\alpha_{12, t-1}$ (alpha 1B) & $\beta_{i, t-1}$ (beta 1) & $\alpha_{C H N, t-1}($ alpha 2) & $\beta_{C H N, t-1}$ beta 2 \\
\hline \hline AUS & -0.0000004 & -0.047355 & 0.068774 & 1.013946 & 0.001652 & -0.001334 \\
\hline Z-score & -0.936393 & -0.905473 & 2.338433 & 23.72226 & 1.796503 & -1.209913 \\
\hline P-value & 0.3491 & 0.3652 & 0.0194 & 0.0000 & 0.0724 & 0.2263 \\
\hline HK & 0.000048 & 0.098454 & 0.015793 & 0.450597 & -0.000335 & -0.002637 \\
\hline Z-score & 257.3128 & 1.211975 & 0.093803 & 6.163212 & -0.179130 & -1.687214 \\
\hline P-value & 0.0000 & 0.2255 & 0.9253 & 0.0000 & 0.8578 & 0.0916 \\
\hline SNG & 0.000078 & -0.087972 & 0.022322 & -0.415416 & 0.004719 & -0.000982 \\
\hline Z-score & 82.67039 & -2.532552 & 0.325646 & -2.013222 & 2.430967 & -0.409860 \\
\hline P-value & 0.0000 & 0.0113 & 0.7447 & 0.0441 & 0.0151 & 0.6819 \\
\hline JPN & 0.000135 & 0.008171 & 0.148705 & 0.359187 & -0.002194 & -0.004332 \\
\hline Z-score & 978.6048 & 0.182855 & 0.787184 & 4.354439 & -1.843893 & -4.369477 \\
\hline P-value & 0.0000 & 0.8549 & 0.4312 & 0.0000 & 0.0652 & 0.0000 \\
\hline US & 0.000033 & 0.057233 & -0.068353 & 0.041939 & 0.000283 & 0.005384 \\
\hline Z-score & 0.668268 & 0.468842 & -0.568521 & 0.031522 & 0.160154 & 0.756566 \\
\hline P-value & 0.5040 & 0.6392 & 0.5697 & 0.9749 & 0.8728 & 0.4493 \\
\hline
\end{tabular}

Table 12: VARMA-AGARCH period 1 (27/08/1991)-(30/6/1992)

The results for the VARMA-AGARCH model for period 2 are slightly stronger than in the previous period. In the case of the Australian market, the significant terms are the past forecasts of volatility in Australia, previous shocks in the Chinese market and previous forecasts of volatility in the Chinese market. The Hong Kong market is surprising, as there is no evidence of any spillovers from the Chinese market, yet all the terms for the domestic market are significant, though previous negative shocks are only significant at10\%. The results for Singapore are virtually the same, with no influence from the Chinese market. The Japanese case is very different, with all terms in the equation being significant with the exception of previous negative shocks in Japan, and the two terms capturing the influences of the Chinese market are only significant at $10 \%$. Finally, the model works well for the US market in this period, with all terms significant, apart from previous positive shocks in the US and prior forecasts of volatility in China. Thus, this period is quite surprising, with all markets showing spillover effects, apart from Singapore and Hong Kong. 


\begin{tabular}{|c||c||c||c||c||c||c|}
\hline & $\omega$ (constant) & $\alpha_{i 1, t-1}$ (alpha 1A) & $\alpha_{12, t-1}$ (alpha 1B) & $\beta_{i, t-1}$ (beta 1) & $\alpha_{C H N, t-1}($ alpha 2) & $\beta_{C H N, t-1}$ beta 2 \\
\hline \hline AUS & -0.0000002 & 0.003908 & 0.013161 & 1.000567 & -0.000472 & 0.000371 \\
\hline Z-score & -1.417101 & -0.498392 & 1.189008 & 214.5956 & -3.229641 & 2.256535 \\
\hline P-value & 0.1565 & 0.6182 & 0.2344 & 0.0000 & 0.0012 & 0.0240 \\
\hline HK & 0.000005 & 0.041565 & 0.073293 & 0.896545 & 0.002139 & -0.002132 \\
\hline Z-score & 2.275230 & 2.265729 & 1.796443 & 35.31832 & 1.407105 & -0.974211 \\
\hline P-value & 0.0229 & 0.0235 & 0.0724 & 0.0000 & 0.1594 & 0.3300 \\
\hline SNG & 0.000018 & 0.101611 & 0.151499 & 0.598295 & -0.000105 & -0.000242 \\
\hline Z-score & 3.082117 & 2.922490 & 1.888158 & 6.940181 & -0.425217 & -0.244068 \\
\hline P-value & 0.0021 & 0.0031 & 0.0590 & 0.0000 & 0.6707 & 0.8072 \\
\hline JPN & 0.000115 & 0.130341 & 0.035565 & 0.558340 & -0.001833 & -0.005631 \\
\hline Z-score & 9.32324 & 2.098558 & 0.035565 & 14.77991 & -1.697100 & -1.935354 \\
\hline P-value & 0.0000 & 0.0359 & 0.6985 & 0.0000 & 0.0897 & 0.0529 \\
\hline US & 0.000002 & -0.033736 & 0.153336 & 0.869889 & -0.000113 & 0.000284 \\
\hline Z-score & 2.724875 & -1.491537 & 4.136882 & 20.43731 & -2.053069 & 1.502731 \\
\hline P-value & 0.0064 & 0.1358 & 0.0000 & 0.0000 & 0.0401 & 0.1329 \\
\hline
\end{tabular}

Table 13: VARMA-AGARCH period $2(01 / 07 / 1992-31 / 12 / 1996)$

Table 14 presents the VARMA-AGARCH results for period 3 running from 1/1/1997 until 29/12/2006. Given the importance of China as Australia's trading partner it is perhaps not surprising that Australia displays strong evidence of spillover effects from China in this period. Indeed there is significant evidence of spillover effects from the Chinese market. Every term in the VARMA-AGARCH equation is significant, with the exception of past positive shocks in the Australian market, while past shocks in the Chinese market are only significant at $10 \%$. The results for all the other markets are disappointing, with no evidence of spillover effects from the Chinese market. The terms for the domestic market are all significant, with the exceptions of the constant terms for the US and Hong Kong markets, and previous positive shocks are only significant at $10 \%$ in these markets. 


\begin{tabular}{|c||c||c||c||c||c||c|}
\hline & $\omega$ (constant) & $\alpha_{i 1, t-1}$ (alpha 1A) & $\alpha_{12, t-1}$ (alpha 1B) & $\beta_{i, t-1}$ (beta 1) & $\alpha_{C H N, t-1}($ alpha 2) & $\beta_{C H N, t-1}$ beta 2 \\
\hline \hline AUS & 0.000008 & -0.001736 & 0.125589 & 0.881087 & 0.004243 & -0.011107 \\
\hline Z-score & 4.872883 & -0.149998 & 4.760518 & 44.32982 & 1.646520 & -2.796240 \\
\hline P-value & 0.0000 & 0.8808 & 0.0000 & 0.0000 & 0.0997 & 0.0052 \\
\hline HK & 0.000001 & 0.022841 & 0.079545 & 0.928687 & 0.003990 & -0.002786 \\
\hline Z-score & 1.548690 & 1.705576 & 4.193383 & 89.52766 & 0.785947 & -0.306634 \\
\hline P-value & 0.1215 & 0.0881 & 0.0000 & 0.0000 & 0.4319 & 0.7591 \\
\hline SNG & 0.000002 & 0.052676 & 0.088368 & 0.893426 & 0.001989 & -0.003623 \\
\hline Z-score & 2.113244 & 2.987649 & 3.384163 & 57.93032 & 0.363759 & -0.417547 \\
\hline P-value & 0.0346 & 0.0028 & 0.0007 & 0.0000 & 0.7160 & 0.6763 \\
\hline JPN & 0.000008 & 0.039709 & 0.085348 & 0.887729 & 0.010060 & -0.017181 \\
\hline Z-score & 3.567557 & 2.908474 & 3.408843 & 49.82757 & 1.446664 & -1.546267 \\
\hline P-value & 0.0004 & 0.0036 & 0.0007 & 0.0000 & 0.1480 & 0.1220 \\
\hline US & 0.0000002 & -0.018089 & 0.135975 & 0.941687 & 0.001600 & 0.005696 \\
\hline Z-score & 1.463050 & -1.652211 & 6.727337 & 91.89245 & -0.892986 & 2.196558 \\
\hline P-value & 0.1435 & 0.0985 & 0.0000 & 0.0000 & 0.3719 & 0.0281 \\
\hline
\end{tabular}

Table 14: VARMA-AGARCH period $3(\mathbf{0 1 . 0 1 / 1 9 9 7 - 2 9 / 1 2 / 2 0 0 6 )}$

Table 15 provides the results for the fourth period, running from the beginning of 2007 until $17 / 11 / 2010$, and therefore incorporating the effects of the GFC. The results here are the weakest of all, and there is no sign of any spillover effects from the Chinese market to the others ones. The domestic market terms for the VARMA-AGARCH model work well. It is perhaps not suprising that the term $\alpha_{1 B}$ is highly significant in every market, as this captures the impact of negative shocks. By contrast, the term $\alpha_{1 A}$, which captures the impact of positive shocks, is insignificant in every market. The constant is insignificant for the Singapore market and is only significant at $10 \%$ in Japan and the USA. This clearly is a bear market. 


\begin{tabular}{|c||c||c||c||c||c||c|}
\hline & $\omega$ (constant) & $\alpha_{i 1, t-1}$ (alpha 1A) & $\alpha_{12, t-1}$ (alpha 1B) & $\beta_{i, t-1}$ (beta 1) & $\alpha_{C H N, t-1}($ alpha 2) & $\beta_{C H N, t-1}$ beta 2 \\
\hline \hline AUS & 0.000014 & 0.038352 & 0.246958 & 0.810282 & 0.001681 & -0.003379 \\
\hline Z-score & 2.678745 & 1.311058 & 4.351436 & 30.96840 & 0.120604 & -0.195401 \\
\hline P-value & 0.0074 & 0.1898 & 0.0000 & 0.0000 & 0.9040 & 0.8451 \\
\hline HK & 0.000009 & 0.038287 & 0.189588 & 0.843787 & -0.009436 & 0.005996 \\
\hline Z-score & 26.76791 & 1.449627 & 4.144194 & 35.84751 & -1.055220 & 0.510055 \\
\hline P-value & 0.0000 & 0.1472 & 0.0000 & 0.0000 & 0.2913 & 0.6100 \\
\hline SNG & 0.000002 & 0.023399 & 0.170545 & 0.881123 & -0.002777 & 0.004592 \\
\hline Z-score & 1.561306 & 1.014124 & 4.201891 & 43.13029 & -0.750600 & 0.781754 \\
\hline P-value & 0.1185 & 0.3105 & 0.0000 & 0.0000 & 0.4529 & 0.4344 \\
\hline JPN & 0.000004 & 0.024575 & 0.107237 & 0.896026 & 0.000374 & 0.001581 \\
\hline Z-score & 1.851826 & 1.422802 & 2.742758 & 36.42459 & 0.065968 & 0.209163 \\
\hline P-value & 0.0641 & 0.1548 & 0.0061 & 0.0000 & 0.9474 & 0.8343 \\
\hline US & 0.000003 & -0.012611 & 0.160177 & 0.910351 & -0.000113 & 0.001203 \\
\hline Z-score & 1.822730 & -0.738734 & 5.914561 & 57.11266 & -0.026252 & 0.161194 \\
\hline P-value & 0.0683 & 0.4601 & 0.0000 & 0.0000 & 0.9791 & 0.8719 \\
\hline
\end{tabular}

Table 15: VARMA-AGARCH period $4(\mathbf{0 1 . 0 1 / 2 0 0 7 - 1 7 / 1 1 / 2 0 1 0 )}$

\section{Conclusion}

All of the markets have shown a significant increase in $\alpha_{1 B}$ in period 4. This coefficient measures the relationship between volatility and lagged negative returns. This is also consistent with the fact that, during the GFC, huge losses were associated with a significant loss of investor confidence, bankruptcies of some of the most established financial institutions around the world (in the USA, in particular), and investors exiting the market in a hurry in order to try and cut their losses. This resulted in a period of extremely high volatility, and established a direct and positive relationship between negative returns and volatility. That is to say, as losses increased, so did the volatility in each of the markets.

Overall, the three models give fairly similar results. The GARCH $(1,1)$ demonstrated little evidence of a volatility spillovers, and on the few occasions where the spillover proved to be statistically significant, the size of the spillover (as indicated by the size of the $\beta_{2}$ coefficient) and the predictive power of the equations (as indicated by the value of $\mathrm{R}$-squared) were so small as to be negligible. However, all of the markets demonstrated a significant GARCH effect, revealing that their current volatility can be explained to some degree by their lagged volatility. The degree of impact of lagged volatility on current volatility changed from market to market, but in most cases the $\beta_{1}$ coefficient remained around 0.9 .

The VARMA-GARCH model produced similar results. The model is a multivariate model, where the equation relates a market's volatility to its own lagged volatility and lagged residual, as well as those of the China. The VARMA-GARCH revealed that, although all of the markets tested, with the exception of the USA, showed some evidence of volatility spillovers from China during periods 1 and/or 2, none showed any evidence of spillovers during periods 3 and 4 . Even those markets that did show evidence of spillovers during the first two periods had coefficients so small as to not be significant in any way - the largest coefficient was 0.002852 (in absolute terms). However, all of the markets showed significant GARCH effects, meaning that their volatility did depend on their own lagged squared residual and volatility. 
The VARMA-AGARCH produced different results yet again. The VARMA-AGARCH is a multivariate model, which is an extension of the VARMA-GARCH model. However it is an asymmetric model - it relates a market's volatility to it's own lagged volatility, but has two separate coefficients for negative and positive returns, as well as the lagged squared residual and lagged volatility for the China. All of the markets showed a significant GARCH effect for each period, except for the USA in period 1. The different markets showed different relationships for positive and negative returns throughout the period. However, one common theme was the positive relationship between negative returns and volatility in periods 3 and 4 , suggesting that 'bad news' increases volatility in the market while 'good news', despite being significant in SNG and JPN in period 2 and 3, does not have the same impact on volatility, as can be seen by the size of the coefficients and their general insignificance in most of the markets tested in most periods.

With regard to volatility spillovers, VARMA-AGARCH produces similar results to those of VARMA-GARCH. Every market that was tested, with the exception of HK, showed some volatility spillovers from China during at least one of the time periods tested. However, the inconsistency of the spillovers, as indicated by the significance of the coefficients, and the size of the coefficients when they were significant, reveals that, although there was some spillover of volatility from China to the other markets, the magnitude of the spillovers is relatively small. The most pronounced evidence of volatility spillover, in the VARMA-AGARCH model appears to be from China to Australia, which is not surprising given the importance of China to Australia as a major trading partner. 
[1] Barth, J. R., R. Koepp, and Z. Zhou, Banking Reform in China: Catalyzing the Nation's Financial Future, (2004) Available at SSRN: http://papers.ssrn.com/sol3/papers.cfm?abstract_id $=548405$

[2] Bauwens, L., S. Laurent, and J. V. K. Rombouts, Multivariate GARCH Models: A Survey, CORE Discussion Paper No. 2003/31. (2003) Available at SSRN: http://ssrn.com/abstract $=411062$

[3] Bollerslev, T. Generalized Autoregressive Conditional Heteroscedasticity, Journal of Econometrics, 31, (1986) 307-327.

[4] Bollerslev, T. Modelling the Coherence in Short-Run Nominal Exchange Rates: A Multivariate Generalized ARCH Model, Review of Economics and Statistics, 72, (1990) 498-505.

[5] Breslin, S. 'Made in China': the Growth of Chinese Trade, CSGR Working Paper No. 19/98. (1998) Available at SSRN: http://ssrn.com/abstract=146957

[6] N. B. S. China, Gross Domestic Product, (2007), from http://www.stats.gov.cn/english/statisticaldata.

[7] Chang, G. H. The Chinese Economy in the Asian Financial Crisis: The Prospect of Renminbi, Cambridge, Harvard Institute for International Development: 20 (1998)

[8] Engle, R.F. Autoregressive Conditional Heteroskedasticity With Estimates of the Variance of UK Inflation, Econometrica 50 (1982): 987-1008.

[9] Engle, R. F. "GARCH 101: An Introduction to the Use of Arch/Garch Models in Applied Econometrics." Journal of Economic Perspectives,15, 4 (2001) 157-168

[10] Engle, R. F. and V. K. Ng, Time-Varying Volatility and the Dynamic Behavior of the Term Structure, Journal of Money, Credit and Banking 25(3): (1993) 336-349.

[11] Gokcan, S. Forecasting volatility of emerging stock markets: linear versus non-linear GARCH models, Journal of Forecasting 19, (2000) 499-504.

[12] Green, S. P. Equity Politics and Market Institutions: The Development of Stock Market Policy and Regulation in China, 1984-2003. (2004). Available at SSRN: http://ssrn.com/abstract $=509342$

[13] Glosten, L.R., R. Jagannathan and D. Runkle, On the Relation Between the Expected Value and the Volatility of the Nominal Excess Return on Stocks, Journal of Finance, 48, (1993) 1779-1801.

[14] Hamao, Y., Masulis, R.W., Ng, V. Correlations in Price Changes and Volatility across International Stock Markets, The Review of Financial Studies 3(2) (1990) 281-307.

[15] Harris, R. D. F., E. Stoja, and J. Tucker. A simplified approach to modeling the co-movement of asset returns, Journal of Futures Markets 27(6) (2007) 575-598. 
[16] Harvey, C. R. and A. R. Siddique, Autoregressive Conditional Skewness, Fuqua School of Business Working Paper No. 9604. (1999) Available at SSRN: http://ssrn.com/abstract $=61332$ or doi:10.2139/ssrn.61332

[17] Johansson, A. C. and C. Ljungwall, Spillover Effects among the Greater China Stock Markets, World Development, 37, 4, (2009) 839-851.

[18] Lima, L. R. and B. P. Neri (2007). "Comparing Value-at-Risk Methodologies." Brazilian Review of Econometrics 27(1): 1-25.

[19] Ling, S., and M. Mcaleer, Asymptotic Theory For A Vector ARMA-GARCH Model, Econometric Theory, 19(2), (2003) 280-310.

[20] McAleer, M. Automated inference and learning in modeling financial volatility, Econometric Theory, 21, (2005) 232-261.

[21] McAleer, M., Chan, F., Hoti, S., and Lieberman, O. (2008). Generalized Autoregressive Conditional Correlation, Econometric Theory, 24(6), 1554-1583.

[22] McAleer, M., F. Chan and D. Marinova, An econometric analysis of asymmetric volatility: theory and application to patents, Journal of Econometrics, 139, (2007) 259-284.

[23] Manera, M., M. McAleer, and M. Grasso, Modelling time-varying conditional correlations in the volatility of Tapis oil spot and forward returns, Applied Financial Economics 16(7) (2006) $525-533$.

[24] Manganelli, S. and R. F. Engle, Value at Risk Models in Finance, ECB Working Paper No. 75. (2001) Available at SSRN: http://ssrn.com/abstract $=356220$

[25] McAleer, M., S. Hoti, and F. Chan, (2009). "Structure and Asymptotic Theory for Multivariate Asymmetric Conditional Volatility." Econometric Reviews 28(5) (2009) $422-440$.

[26] Moon G.H and W.C. Yu, Volatility Spillovers between the US and the China Stock Markets: Structural Break Test with Symmetric andAsymmetric GARCH Approaches," Glob. Econ. Review, 39(2) (2010) 129-149.

[27] Nelson, D. B. Conditional Heteroskedasticity in Asset Returns: A New Approach, Econometrica 59(2) (1991) 347-370.

[28] So, M. K. and A. S. L. Tse, Dynamic Modeling of Tail Risk: Applications to China, Hong Kong and Other Asian Markets, Asia-Pacific Financial Markets, 16 (2009) 183210.

[29] Yao, Y. Perspective of China Stock Market Under Global Financial Uncertainty, (2002) Available at SSRN: http://ssrn.com/abstract $=354540$

[30] Yi, Z., H. Chen, Sr., and W.K Wong, China s Stock Market Integration with a Leading Power and a Close Neighbor, (2010) Available at SSRN: http://ssrn.com/abstract $=1547665$ 
[31] Yilmaz, K. Return and Volatility Spillovers Among the East Asian Equity Markets, Journal of Asian Economics, 21, 3, (2010) 304-313.

[32] Zhang, B. and X. Li, "The asymmetric behaviour of stock returns and volatilities: evidence from Chinese stock market, Applied Economics Letters, 15 (2008) 959-962. 